\title{
Capsaicin for Neuropathic Pain: Linking Traditional Medicine and Molecular Biology
}

\author{
Maija Haanpääa ${ }^{2}$ Rolf-Detlef Treede ${ }^{b}$ \\ a Department of Neurosurgery, Helsinki University Central Hospital, Töölö Hospital, Helsinki, Finland; \\ ${ }^{b}$ Lehrstuhl für Neurophysiologie, Medizinische Fakultät Mannheim, Universität Heidelberg, Mannheim, Germany
}

\section{Key Words}

Capsaicin · Neuropathic pain - TRPV1 · Nociceptor ·

Hyperalgesia

\begin{abstract}
Capsaicin has long been used as a traditional medicine to treat pain and, recently, its mechanism of analgesic action has been discovered. This review article documents the clinical development of capsaicin to demonstrate that pharmacognosy still has a profound influence on modern-day drug development programs. Capsaicin is a highly selective agonist for the transient receptor potential channel vanilloid-receptor type 1 (TRPV1), which is expressed on central and peripheral terminals of nociceptive primary sensory neurons. Knockout studies have revealed the importance of TRPV1 as a molecular pain integrator and target for novel analgesic agents. Topical application of capsaicin at the peripheral terminal of TRPV1-expressing neurons superficially denervates the epidermis in humans in a highly selective manner and results in hypoalgesia. In three recent randomized controlled trials, a patch containing high-concentration capsaicin demonstrated meaningful efficacy and tolerability relative to a low-concentration capsaicin control patch in patients with peripheral neuropathic pain. Data from clinical practice will determine if the high-concentration capsaicin patch is effective in real-world settings.

Copyright ๑ 2012 S. Karger AG, Basel
\end{abstract}

\section{Introduction}

Over the last three millennia, civilizations have attempted to cure sickness with products derived from animal, plant and microbial origins or from mineral sources [1]. About $80 \%$ of the populations of some Asian and African countries are estimated to rely on traditional medicines as sources for their primary healthcare. Annual revenues for herbal medicines in Western Europe reached EUR 3.5 billion in 2003-2004 [2]. Although the underlying use of many of these so-called natural products clearly lacks scientific logic, several of them nevertheless became founding platforms for modern drug development throughout the twentieth century $[1,3]$.

Three classes of analgesic medications are derived from plant ingredients: opiate receptor agonists from poppy seeds, cyclooxygenase inhibitors from willow bark, and capsaicinoids from chili peppers. Capsaicinoidcontaining preparations are popular natural medicines for pain syndromes and although the chili peppers from which they are derived (Capsicum spp.) were originally found in the Americas, they are now widespread $[4,5]$. Capsaicin of various purities and grades has been widely available in pharmacies as low-to-moderate concentration creams and gels [5-7]. Increased local perfusion and the resulting warming or capsaicin-induced pain leading to counterirritation were initially thought to account for the analgesic effects of capsaicin [5].

\section{KARGER}

Fax +4161306 1234 E-Mail karger@karger.ch www.karger.com
Rolf-Detlef Treede, MD

Lehrstuhl für Neurophysiologie

Medizinische Fakultät Mannheim, Universität Heidelberg

Ludolf-Krehl-Strasse 13-17, DE-68167 Mannheim (Germany)

Tel. +49621383 9926, E-Mail Rolf-Detlef.Treede@medma.uni-heidelberg.de 
Cloning of the capsaicin receptor, i.e. the transient receptor potential channel of the vanilloid receptor family subtype 1 (TRPV1), provided the molecular basis for understanding the various actions of capsaicin [8]. TRPV1 was discovered by an expression cloning strategy utilizing capsaicin-induced increases in intracellular calcium concentration as a marker. The calcium signal not only indicates opening of a nonselective cation channel and depolarization, but also initiation of receptor desensitization and downregulation, and degeneration of epidermal nerve fibers (ENFs), which is referred to as defunctionalization $[5,9,10]$. As a result of neurite degeneration, ENFs become less sensitive to a variety of stimuli (including capsaicin itself), leading to reduced pain responses $[5,10]$. A challenge in capsaicinoid drug development was harnessing the desensitizing action of capsaicin without unnecessarily exposing patients to TRPV1 activation-induced pain.

An early therapeutic approach using a low-dose capsaicin cream formulation to defunctionalize nerve endings in human skin required repeated daily applications over weeks [11]. Although pain arising from such topical capsaicin applications is mild, mucous membranes are highly sensitive to the effects. Thus, each topical exposure to capsaicin can result in irritation of the eyes and respiratory tract [12]. A systematic review of clinical trials using low-dose capsaicin creams described moderate-topoor efficacy in the treatment of chronic neuropathic pain with a number needed to treat of 5.7 [7]. The suboptimal ratio of defunctionalization to irritation with the low-dose capsaicin creams and the lengthy application procedure limited their widespread use $[5,13]$.

Development of structural analogs of capsaicin that retained its antinociceptive attributes without inducing irritation failed in the late 1980s [5]. Although the capsaicin derivative olvanil was 10 times more potent than capsaicin in TRPV1 activation assays and devoid of pungen$c y$, it did not reduce peripheral fiber responsiveness in vitro, possibly because of an alternative mechanism of receptor activation and desensitization $[5,14,15]$.

Initiatives to enhance the clinical effectiveness of capsaicin explored use of high doses (10\% weight by volume $[\mathrm{w} / \mathrm{v}]$ and weight by weight $[\mathrm{w} / \mathrm{w}]$ formulations), which fully desensitize TRPV1-expressing neurons in human skin within a few days or even upon a single application. These creams were useful to determine the actions of TRPV1 expressing neurons in experimental studies of human volunteers $[16,17]$. Whereas pain during application is moderate and tolerable in healthy subjects, it may be too strong for patients with sensitization or upregulation of TRPV1. Therapeutic use of high-dose creams was

Capsaicin for Neuropathic Pain Control halted because of severe application site-associated pain and the risk of capsaicin contamination to the patient and healthcare professional [16].

Recently, a new dermal patch has been developed containing $8 \% \mathrm{w} / \mathrm{w}$ pure trans-capsaicin in the adhesive layer. This formulation, which enables administration of highdose capsaicin with a single treatment, is licensed for use in peripheral neuropathic pain in nondiabetic adults in the European Union and for postherpetic neuralgia (PHN) in the USA $[18,19]$. Pretreating the affected area of skin with a local anesthetic is advised, although doubts have been raised regarding the benefits of such pretreatment $[20,21]$.

The aim of the current review is to discuss aspects of capsaicin pharmacology and advances in this challenging area of analgesic drug development. After appraising the neurophysiological effects and mechanism of analgesic action established in preclinical studies, we show that the early concepts regarding capsaicin use have been translated into clinical application through evidence from randomized controlled trials.

\section{Capsaicin Treatment for Hyperalgesia}

\section{TRPV1 Receptor}

Peripheral nociceptive neurons are pseudo-unipolar neurons situated in sensory ganglia that have a single axon which branches within the ganglion into one peripheral and one central axon. TRPV1 functions as a polymodal receptor on the peripheral terminals of primary afferent neurons $[22,23]$. On the central terminals, TRPV1 may be involved in modulating signal transmission at the first synapse between the dorsal root ganglion or trigeminal ganglion neurons and the dorsal horn or caudal spinal trigeminal nucleus neurons [24-27].

TRPV1 is a ligand-gated, nonselective cation channel and is one of 30 known members of the TRP ion channel family $[8,28]$. TRPV1 is a key receptor involved in the transmission and modulation of pain signals [28], and is an important transducer of noxious stimuli (e.g. heat, low $\mathrm{pH}$ ) and certain chemicals (including capsaicin). TRPV1 is sensitized by inflammatory mediators responsible for inflammatory pain arising from tissue injury [23, 29]. TRPV1 receptor expression increases in some clinical pain conditions, possibly resulting from increased retrograde transport of nerve growth factor to the cell body [30, 31].

\section{Preclinical Studies Targeting the TRPV1 Receptor}

Several molecular biology and pharmacological techniques have been employed to elucidate the role of the 

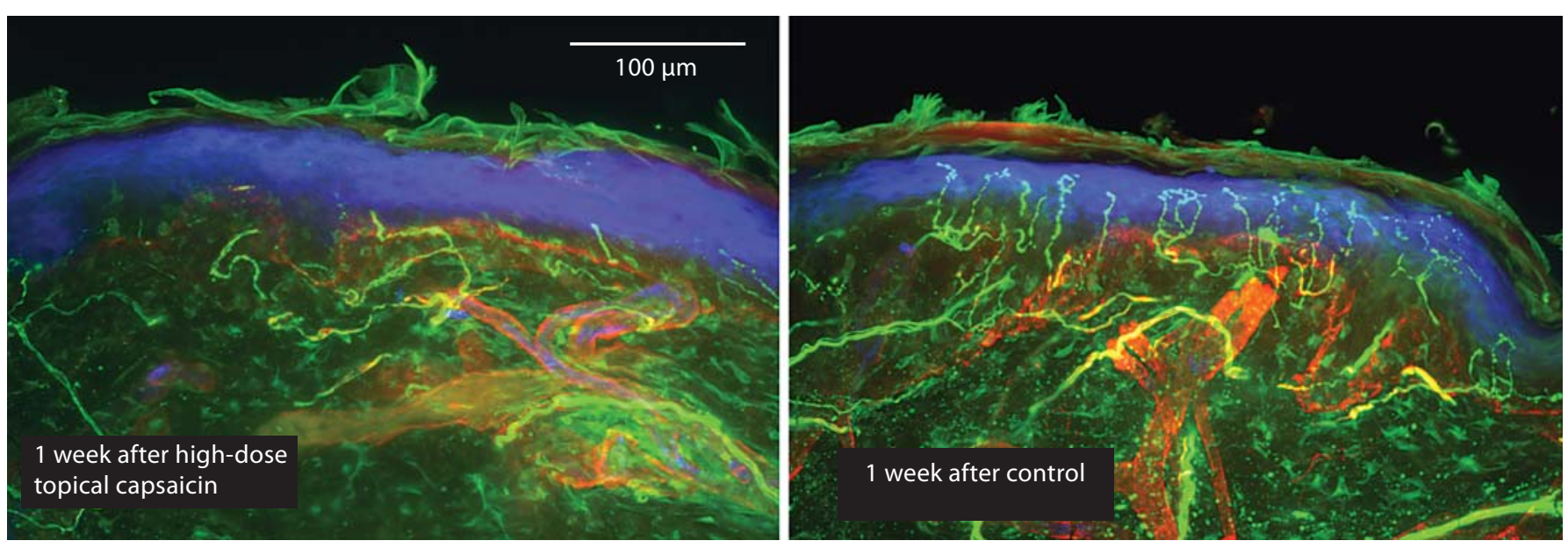

Fig. 1. Intraepidermal nerve fibers retract following high-dose topical capsaicin treatment. Reprinted from Kennedy et al. [43] with permission from Elsevier.

TRPV1 receptor in somatosensory pathways. Rodents lacking the TRPV1 channel are not only insensitive to vanilloid-evoked acute pain, but also exhibit impairment in their ability to detect thermal stimuli and to develop thermal hyperalgesia (table 1) [32-34, 55]. However, responsiveness to noxious heat stimuli is not completely lost in TRPV1 knockout mice. Whereas TRPV1 knockout animals lack a component of sensory transduction in an otherwise intact neuronal circuit, intrathecal injection of capsaicin breaks the connection that all capsaicin-sensitive fibers have with the spinal cord [37]. It has been known for some time that intrathecal administration of capsaicin in rats causes long-lasting loss of heat sensitivity $[35,36,56]$ and can induce selective degeneration of a distinct population of primary sensory neurons involved in the mediation of chemogenic pain [57]. More recent findings in the mouse indicate that pharmacological ablation of the central branches of TRPV1 nociceptors with capsaicin results in a more complete loss of acute sensitivity to heat pain than that observed in knockout constructs (table 1) [37]. However, it should be noted that $80-90 \%$ of neonatal rats desensitized to capsaicin in this way developed wounds, scabs and areas of alopecia [58].

Interestingly, intrathecal administration of resiniferatoxin, a more potent agonist of TRPV1 than capsaicin, to rats and monkeys not only rapidly inhibits nociceptive synaptic transmission but also provides long-lasting analgesia in behavioral models (due to destruction of TRPV1-expressing central sensory nerve terminals) [59, 60]. These data support development of novel analgesics targeting TRPV1-expressing neurons either centrally or peripherally.
The striking difference between the limited effects of TRPV1 gene knockout and the pronounced effects of ablation of TRPV1-positive neurons on nociceptive signal processing is highly relevant for analgesic drug development [61]. While TRPV1 antagonists are anticipated - at best - to mimic the effects of TRPV1 knockout, TRPV1positive neuron ablation can be mimicked by topical application of TRPV1 agonists to target tissues (skin or mucous membranes).

\section{Studies in Human Volunteers}

It is interesting to compare the behavioral effects of topical or intradermal capsaicin in humans with the pronounced changes observed in mice after intrathecal injection of capsaicin, as these procedures involve exposure to capsaicin at the two terminals of the same neuron. Topical exposure to capsaicin in humans leads initially to nociceptor firing and a period of enhanced sensitivity to painful heat stimuli. A refractory period follows during which individuals are relatively resistant to capsaicin and heat but not pinprick stimuli $[17,38,62,63]$, consistent with the existence of a TRPV1-negative population of nociceptors that appear to be specialized for mechanical pain. Defunctionalization following continuous capsaicin exposure is accomplished via a TRPV1 receptor-mediated massive influx of calcium ions into the neuron [64] and the ensuing activation of calcium-sensitive proteases (among other mechanisms), which results in reversible neurite degeneration that can be visualized as reduction in ENFs (fig. 1) [10, 42, 43]. 


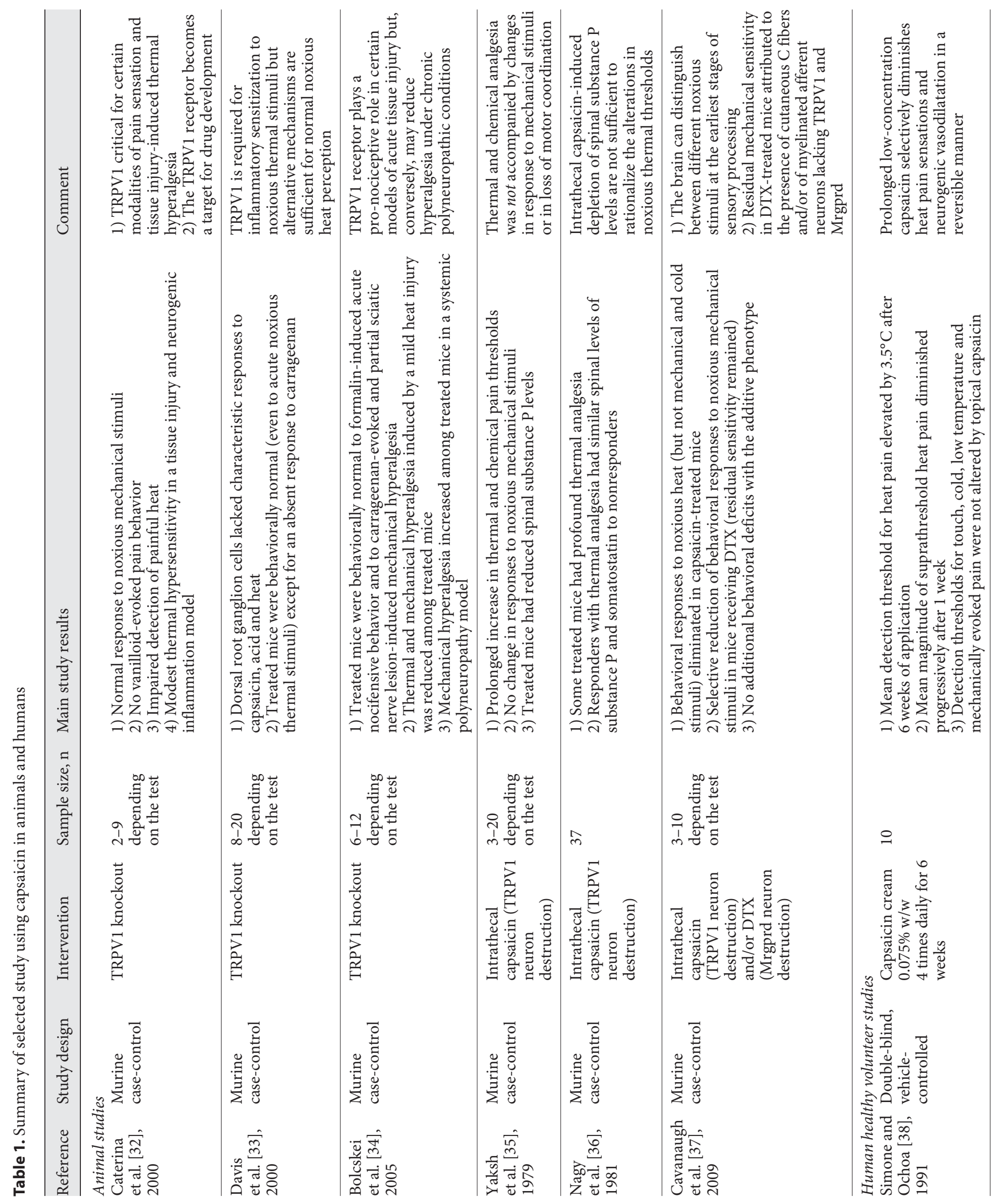




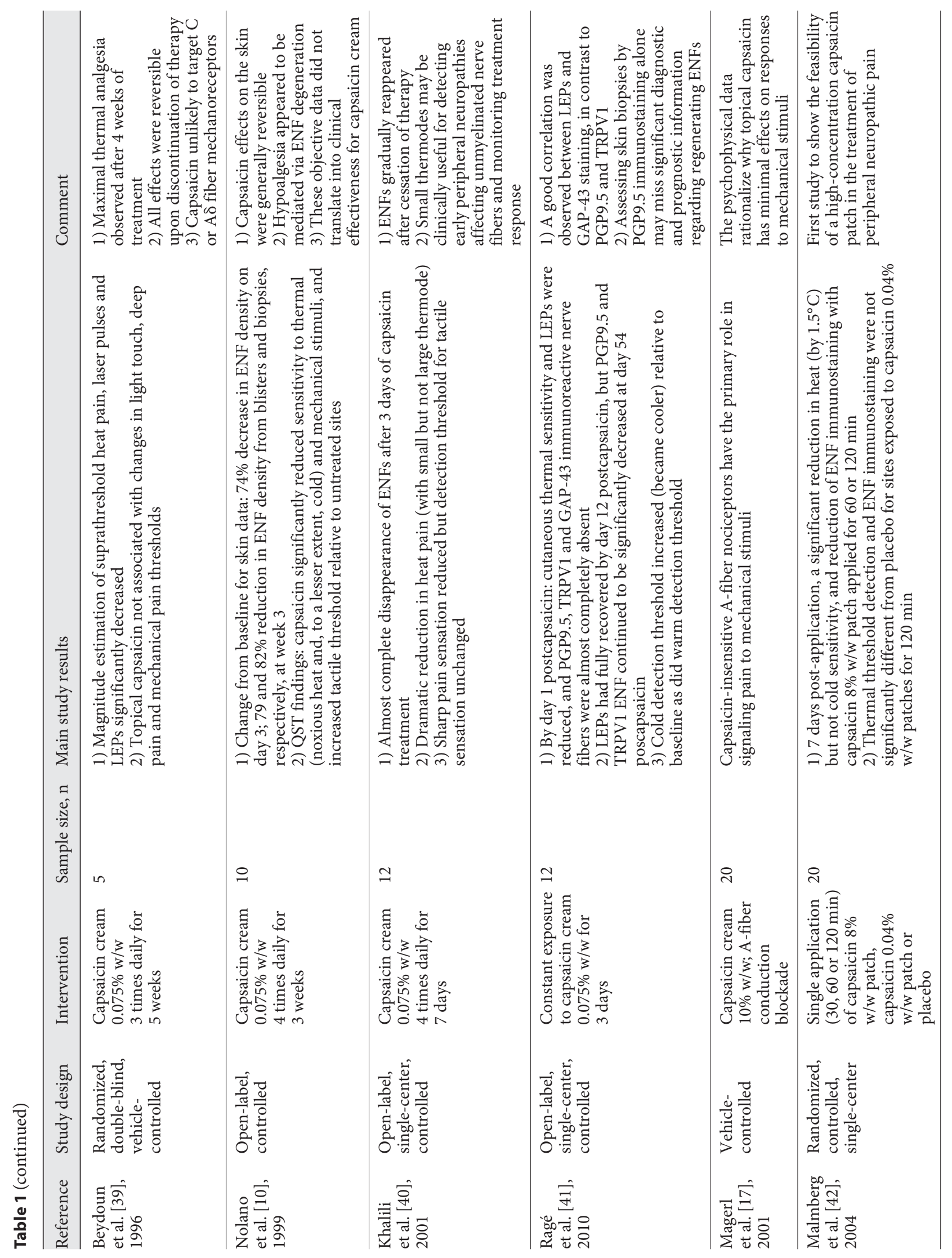




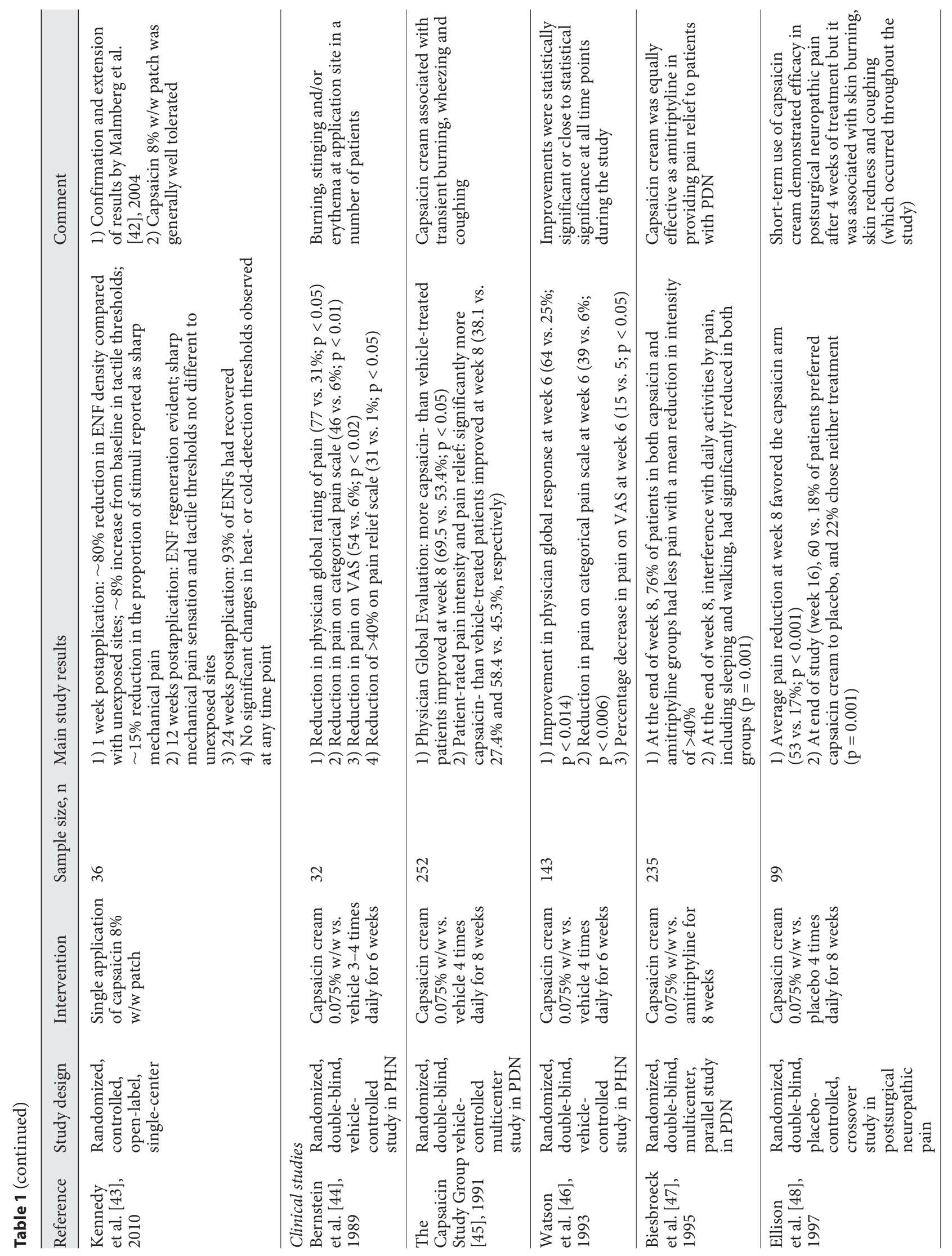




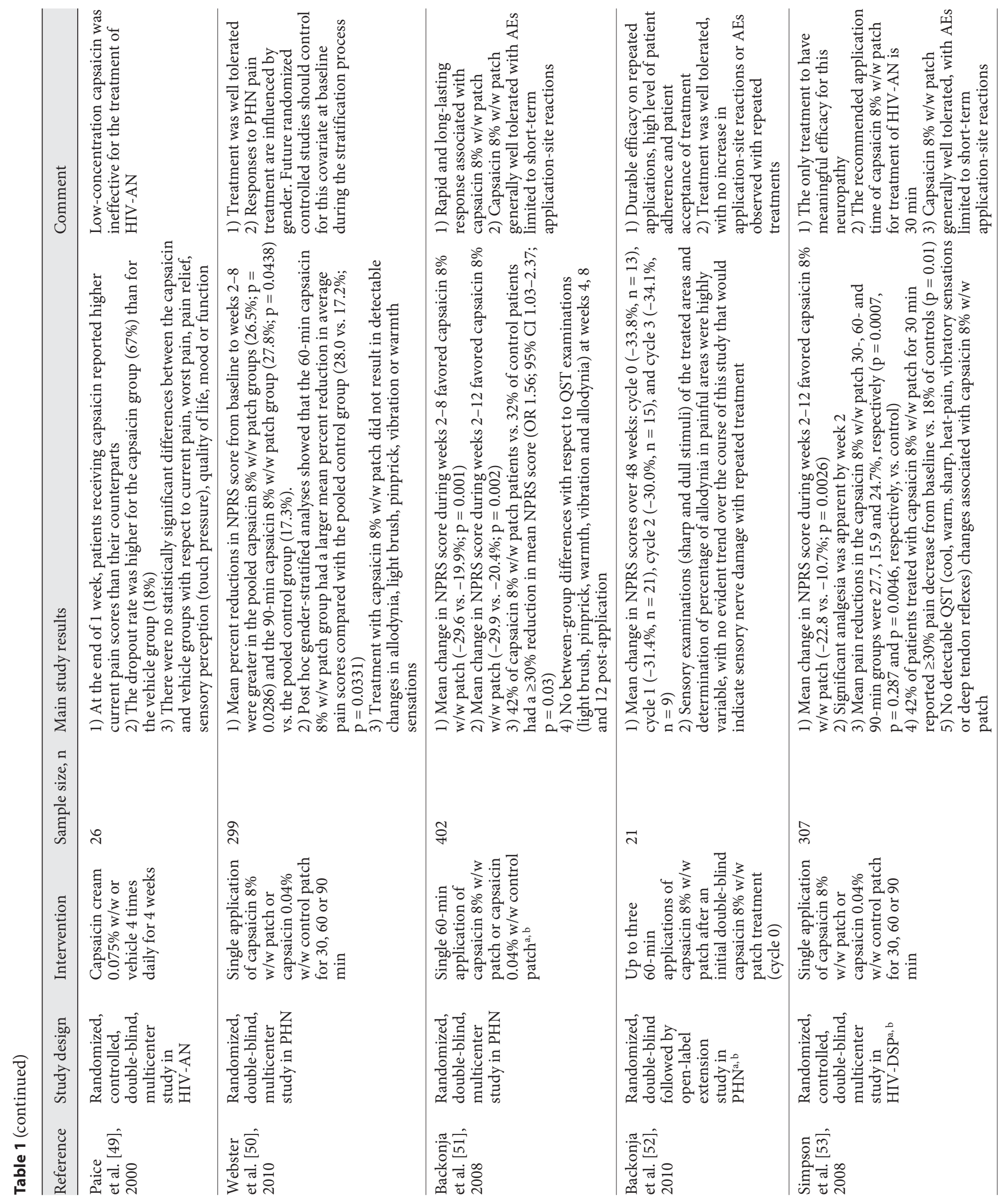




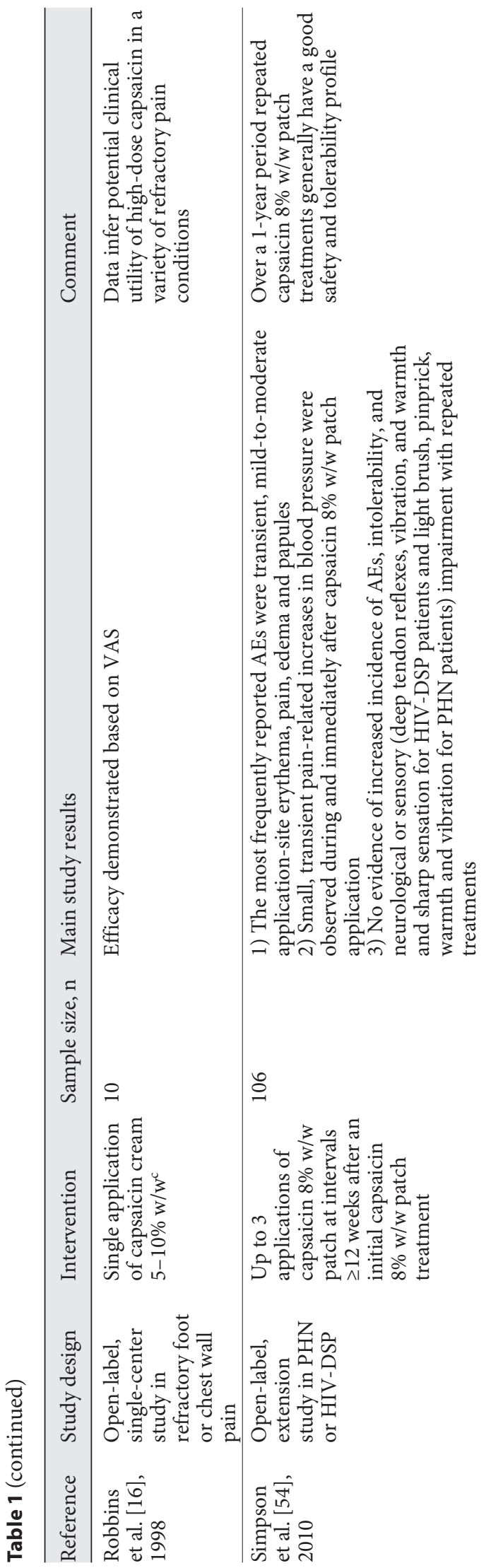

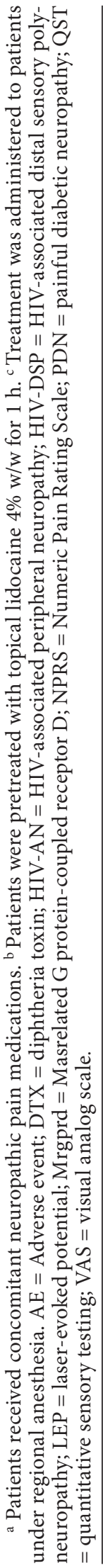

The rate and magnitude of reversible neurite degeneration was demonstrated in skin biopsies of healthy volunteers who received either repeated topical applications of low-dose capsaicin cream $(0.075 \% \mathrm{w} / \mathrm{w})$ over 7 -day and 3 -week treatment periods $[10,40]$ or a single application of a high-concentration capsaicin patch $(8 \% \mathrm{w} / \mathrm{w})$ for 60 min [43]. Overall, the reduction in ENF density was slower and less extensive after repeated application of the lowconcentration capsaicin creams than after a single application of the high-concentration capsaicin patch (table 1). Sensory testing revealed a pronounced reduction in thermal pain sensitivity but not pinprick sensitivity within the first few days after high-dose capsaicin cream $[17,65]$, consistent with animal data. One week after application of the high-dose patch, however, thermal pain sensitivity was normal [43], suggesting relatively rapid recovery of nociceptive function in healthy subjects. A study using laser-evoked potentials and skin biopsies after low-dose capsaicin cream treatment also found a more rapid recovery of thermal pain sensation than ENF density [41].

The laser-evoked potential data indicate that heat-sensitive A-fiber nociceptors are also defunctionalized by capsaicin, whereas capsaicin was not associated with alterations in light touch, deep pain or mechanical pain detection thresholds [39]. Sharp mechanical (pinprick) pain is primarily mediated via capsaicin-insensitive A-fiber nociceptors, which would explain why topical capsaicin had only modest effects on this stimulus [17]. In turn, these data indicate that painful heat is the most adequate stimulus to monitor defunctionalization by capsaicin.

\section{Therapeutic Use}

Low-Concentration Topical Capsaicin

Despite promising pharmacodynamic data describing hypoalgesia accompanied by ENF degeneration in human volunteers [10], low-concentration capsaicin creams $(\leq 0.1 \%)$ have demonstrated poor-to-modest efficacy in neuropathic pain syndromes over the short term (table 1) [44-49]. Explanations for the disappointing results include the low concentration of pure capsaicin used and poor patient adherence $[9,66-68]$.

\section{High-Concentration Topical Capsaicin}

High-concentration capsaicin was first used as a $10 \%$ $\mathrm{w} / \mathrm{v}$ solution in 10 patients with intractable pain due to bilateral peripheral neuropathy but this approach was terminated due to severe pain on application (despite regional analgesia) and risk of aerosol contamination [16]. More recently, a dermal patch has been developed containing a high concentration of synthetic pure trans-cap- 
saicin $(8 \% \mathrm{w} / \mathrm{w})$ in the adhesive layer (QUTENZA ${ }^{\mathrm{TM}}$; NGX-4010). Advances in stereoselective medicinal chemistry have facilitated synthesis of pure trans-capsaicin (99\%), which is identical to the naturally occurring molecule $[9,67]$. The synthetic process delivers higher concentrations of active trans-capsaicin than can be extracted from capsicums [67]. The high-concentration patch demonstrated efficacy in patients with PHN and in those with HIV-associated distal sensory polyneuropathy (HIV-DSP) (table 1) [51-54]. Lack of unnecessary exposure to capsaicin during the application and removal procedure represents a practical tolerability advantage of the patch over capsaicin creams. In addition, only one treatment is required every 3 months (or longer depending on pain control status).

In contrast to the clinical trial data for low-concentration capsaicin creams, the clinical efficacy data for the $8 \%$ capsaicin patch are entirely consistent with skin biopsy data. In double-blind randomized trials that used a lowdose capsaicin patch $(0.04 \% \mathrm{w} / \mathrm{w})$ as an active control to maintain blinding, a single application of the $8 \%$ capsaicin patch produced rapid and prolonged pain relief in patients with moderate-to-severe PHN or HIV-DSP, irrespective of whether they were receiving concomitant medications for neuropathic pain (table 1) [51-53].

A 60 -min application of the $8 \%$ capsaicin patch shown to be effective in patients with PHN [50] - exerted its maximum therapeutic effect as early as 2 days after application [51]. Significantly more patients treated with the $8 \%$ capsaicin patch reported a $\geq 30 \%$ pain decrease from baseline than control patients ( 42 vs. $32 \%$; $p=0.04$ ) [51]. Furthermore, the proportion of patients reporting an improvement on the Patient Global Impression of Change scale was significantly higher among those treated with the $8 \%$ capsaicin patch compared with those treated with the control at both week 8 (53 vs. $42 \%$; $\mathrm{p}=$ 0.03 ) and week 12 (55 vs. 43\%; p = 0.04) [51]. Similarly, a dose-finding study in patients with HIV-DSP revealed that a single 30 - or 120 -min (but not 60-min) application of the $8 \%$ capsaicin patch provided meaningful pain relief within 2 weeks, which persisted throughout the 12-week observation period [53]. The proportion of patients who reported a $\geq 30 \%$ pain decrease from baseline was $>2$ fold greater in the group treated with the $8 \%$ capsaicin patch than the control group (42 vs. $18 \% ; \mathrm{p}=0.01$ ) [53]. The importance of these positive trial data cannot be understated as there are very few, if any, other treatments with proven effectiveness in HIV-DSP [69]. Two openlabel studies, which followed patients for a total of 48 weeks after their first treatment, have shown that re-ap- plication of the $8 \%$ capsaicin patch results in reproducible tolerability and safety, and suggest that a comparable degree of pain relief can be achieved with each retreatment (table 1) [52, 54].

The clinical efficacy of the $8 \%$ capsaicin patch for treatment of PHN and HIV-DSP has been confirmed in two independent meta-analyses $[70,71]$ and the European Federation of Neurological Societies have included the $8 \%$ capsaicin patch in recent guidelines on the pharmacological treatment of neuropathic pain [69]. Further studies are now needed to identify those patients who get the most pain relief and to identify other peripheral neuropathic pain syndromes that may respond to treatment with the $8 \%$ capsaicin patch. Patients with heat hyperalgesia, who make up about $18 \%$ of patients with neuropathic pain [72], are likely candidates.

\section{Capsaicin Safety}

Intradermal capsaicin administration leads to irreversible loss of TRPV1 neurons due to systemic distribution in newborn rodents [73, 74], and to transient TRPV1 denervation at the injection site in human adults [75]. Repeated, long-term application of topical capsaicin to the rat hind paw did not damage the sciatic nerve or result in neuron loss in the dorsal root ganglion [76].

High-level dietary intake of capsaicin is not associated with any safety concerns in humans. The estimated highest capsaicin dietary exposure (in India, Mexico and Thailand) is $25-200 \mathrm{mg} /$ day [77] and the total capsaicin content of one $8 \%$ capsaicin patch is within that range (179 mg per patch, of which only a fraction is absorbed). Systemic absorption of capsaicin is very low following a 60- or 90 -min application of the $8 \%$ capsaicin patch, with a maximum plasma concentration of $17.8 \mathrm{ng} / \mathrm{ml}$ observed in any patient [78]. Systemic exposure to capsaicin following $8 \%$ capsaicin patch application is also transient as capsaicin levels decline rapidly with a mean population elimination half-life of $1.6 \mathrm{~h}$. Furthermore, detectable levels of capsaicin metabolites were not observed in any patients. Therefore, treatment with the $8 \%$ capsaicin patch is unlikely to result in systemic side effects or to alter the systemic metabolism of concomitant medications. In clinical trials, topical application of capsaicin was generally well tolerated and associated with transient application-site reactions such as pain and erythema (table 1).

It is important to evaluate the safety of topical capsaicin in patients with diabetes as they likely have ongoing neurodegenerative processes that might be exacerbated by capsaicin. Case-control data indicate that ENF regeneration after low-dose capsaicin is slower among patients 
with diabetes even when these patients had no evidence of neuropathy [79]. Moreover, caution should be exercised when applying topical capsaicin to skin at risk of ulceration [80]. Two small studies of patients with painful diabetic neuropathy reported the encouraging finding that topical capsaicin cream had no adverse effects on sensory function or neurovascular control [81, 82], but more safety data, using both morphological (ENF) and functional assessments (heat pain, laser-evoked potentials), are needed before this treatment can be recommended for patients with diabetes (currently a contraindication).

\section{Discussion}

A better understanding of the molecular and cellular effects of capsaicin has helped rationalize the popularity of this molecule as a means of assuaging pain. Theories on the mechanism of action of capsaicin have shifted from increased perfusion and counterirritation to defunctionalization. Defunctionalization of the entire population of TRPV1-expressing neurons is more efficient in reducing pain behavior in animals than knockout of TRPV1. Likewise in humans, defunctionalization by high-dose patches has been found effective in meta-analyses of clinical trials, whereas TRPV1-antagonists have yet to be approved (they are also burdened by adverse effects such as fever, hypertension and gastric ulceration [29]). Both low-dose and high-dose topical capsaicin are listed as effective in the most recent meta-analysis on neuropathic pain therapy [71]. Of all the effective therapies, the high-dose patch is unique in that it can deliver up to 12 weeks of pain relief from a single application, whereas all other therapies were evaluated for continuous treatment over the same period of time. At the clinic, activation of TRPV1 by topical application of the $8 \%$ capsaicin patch translated into meaningful pain relief from PHN and HIV-DSP.

In conclusion, the capsaicin story is a valuable case study describing how pharmacognosy can provide valuable and necessary inputs into rational drug design, and how medicinal chemistry and neurobiology can improve traditional medicines. For the capsaicin patch, the difficult step of translating efficacy in defunctionalizing nociceptive neurons in animal models to pain relief in human patients was greatly facilitated by pre-existing clinical experience with topical capsaicin preparations that had been in use before the understanding of its molecular basis of action.

\section{Acknowledgements}

Editorial assistance and evidence tables were provided by Malcolm Darkes at Adelphi Communications, supported by Astellas Europe Ltd.

\section{Disclosure Statement}

M.H. has lectured or served on advisory boards for the following companies in the past 24 months: Abbott, Astellas, Astra Zeneca, Eli Lilly, Janssen Cilag, Medtronic, MSD, Mundipharma, Pfizer and Sanofi-Pasteur, and has participated in international congresses as a guest of Astellas, Medtronic and Pfizer. RDT has lectured or served on advisory boards for or received grants from the following companies in the past 24 months: Astellas, Boehringer Ingelheim, Galderma, Grünenthal, Kade, Eli Lilly, Merz, Nycomed, Pfizer.

\section{References}

1 Sneader W: The legacy of the past; in: Drug Discovery: the Evolution of Modern Medicine. Chichester, Wiley, 1985, pp 1-14.

2 World Health Organization: Traditional Medicine, 2008.

3 Sneader W: Sources of drug prototypes; in: Drug Prototypes and Their Exploitation. Chichester, Wiley, 1996, pp 3-10.

-4 Perry L, Dickau R, Zarrillo S, Holst I, Pearsall DM, Piperno DR, Berman MJ, Cooke RG, Rademaker K, Ranere AJ, Raymond JS, Sandweiss DH, Scaramelli F, Tarble K, Zeidler JA: Starch fossils and the domestication and dispersal of chili peppers (Capsicum spp. L.) in the Americas. Science 2007;315: 986-988.

Capsaicin for Neuropathic Pain Contro
5 Szallasi A, Blumberg PM: Vanilloid (capsaicin) receptors and mechanisms. Pharmacol Rev 1999;51:159-212.

-6 Knotkova H, Pappagallo M, Szallasi A: Capsaicin (TRPV1 agonist) therapy for pain relief: farewell or revival? Clin J Pain 2008;24: 142-154.

7 Mason L, Moore RA, Derry S, Edwards JE, McQuay HJ: Systematic review of topical capsaicin for the treatment of chronic pain. BMJ 2004;328:991.

8 Caterina MJ, Schumacher MA, Tominaga M, Rosen TA, Levine JD, Julius D: The capsaicin receptor: a heat-activated ion channel in the pain pathway. Nature 1997;389:816-824. $\checkmark 9$ Noto C, Pappagallo M, Szallasi A: NGX4010, a high-concentration capsaicin dermal patch for lasting relief of peripheral neuropathic pain. Curr Opin Investig Drugs 2009; 10:702-710.

10 Nolano M, Simone DA, WendelschaferCrabb G, Johnson T, Hazen E, Kennedy WR: Topical capsaicin in humans: parallel loss of epidermal nerve fibers and pain sensation. Pain 1999;81:135-145.

11 Watson CP, Evans RJ, Watt VR, Birkett N: Post-herpetic neuralgia: 208 cases. Pain 1988;35:289-297.

12 Cephalon (UK) Limited: Summary of Product Characteristics. Axsain. London, European Medicines Agency, 2011. 
13 Rains C, Bryson HM: Topical capsaicin. A review of its pharmacological properties and therapeutic potential in post-herpetic neuralgia, diabetic neuropathy and osteoarthritis. Drugs Aging 1995;7:317-328.

-14 Dray A, Bettaney J, Rueff A, Walpole C, Wrigglesworth R: NE-19550 and NE-21610, antinociceptive capsaicin analogues: studies on nociceptive fibres of the neonatal rat tail in vitro. Eur J Pharmacol 1990;181:289293.

15 Vriens J, Appendino G, Nilius B: Pharmacology of vanilloid transient receptor potential cation channels. Mol Pharmacol 2009;75: 1262-1279.

16 Robbins WR, Staats PS, Levine J, Fields HL, Allen RW, Campbell JN, Pappagallo M: Treatment of intractable pain with topical large-dose capsaicin: preliminary report. Anesth Analg 1998;86:579-583.

-17 Magerl W, Fuchs PN, Meyer RA, Treede RD: Roles of capsaicin-insensitive nociceptors in cutaneous pain and secondary hyperalgesia. Brain 2001;124:1754-1764.

18 NeurogesX Inc: Investigators Brochure: NGX-4010 (capsaicin patch, 8\% w/w). San Mateo, NeurogesX, 2009.

19 Astellas Pharma Europe Ltd: Summary of Product Characteristics: Qutenza $179 \mathrm{mg}$ Cutaneous Patch. London, European Medicines Agency, 2011.

-20 Fuchs PN, Pappagallo M, Meyer RA: Topical EMLA pre-treatment fails to decrease the pain induced by $1 \%$ topical capsaicin. Pain 1999;80:637-642.

-21 Lam VY, Wallace M, Schulteis G: Effects of lidocaine patch on intradermal capsaicininduced pain: a double-blind, controlled trial. J Pain 2011;12:323-330.

-22 Julius D, Basbaum AI: Molecular mechanisms of nociception. Nature 2001;413:203210.

-23 Tominaga M, Caterina MJ, Malmberg AB, Rosen TA, Gilbert H, Skinner K, Raumann BE, Basbaum AI, Julius D: The cloned capsaicin receptor integrates multiple pain-producing stimuli. Neuron 1998;21:531-543.

-24 Nakatsuka T, Furue H, Yoshimura M, Gu JG: Activation of central terminal vanilloid receptor-1 receptors and alpha beta-methylene-ATP-sensitive P2X receptors reveals a converged synaptic activity onto the deep dorsal horn neurons of the spinal cord. J Neurosci 2002;22:1228-1237.

-25 Baccei ML, Bardoni R, Fitzgerald M: Development of nociceptive synaptic inputs to the neonatal rat dorsal horn: glutamate release by capsaicin and menthol. J Physiol 2003; 549:231-242.

-26 Yang K, Kumamoto E, Furue H, Yoshimura M: Capsaicin facilitates excitatory but not inhibitory synaptic transmission in substantia gelatinosa of the rat spinal cord. Neurosci Lett 1998;255:135-138.
27 Sikand P, Premkumar LS: Potentiation of glutamatergic synaptic transmission by protein kinase C-mediated sensitization of TRPV1 at the first sensory synapse. J Physiol 2007;581:631-647.

28 Caterina MJ, Julius D: The vanilloid receptor: a molecular gateway to the pain pathway. Annu Rev Neurosci 2001;24:487-517.

29 Premkumar LS, Sikand P: TRPV1: A target for next generation analgesics. Curr Neuropharmacol 2008;6:151-163.

30 Tympanidis P, Casula MA, Yiangou Y, Terenghi G, Dowd P, Anand P: Increased vanilloid receptor VR1 innervation in vulvodynia. Eur J Pain 2004;8:129-133.

31 Yilmaz Z, Renton T, Yiangou Y, Zakrzewska J, Chessell IP, Bountra C, Anand P: Burning mouth syndrome as a trigeminal small fibre neuropathy: increased heat and capsaicin receptor TRPV1 in nerve fibres correlates with pain score. J Clin Neurosci 2007;14:864-871.

32 Caterina MJ, Leffler A, Malmberg AB, Martin WJ, Trafton J, Petersen-Zeitz KR, Koltzenburg M, Basbaum AI, Julius D: Impaired nociception and pain sensation in mice lacking the capsaicin receptor. Science $2000 ; 288$ : 306-313.

33 Davis JB, Gray J, Gunthorpe MJ, Hatcher JP Davey PT, Overend P, Harries MH, Latcham J, Clapham C, Atkinson K, Hughes SA, Rance K, Grau E, Harper AJ, Pugh PL, Rogers DC, Bingham S, Randall A, Sheardown SA: Vanilloid receptor-1 is essential for inflammatory thermal hyperalgesia. Nature 2000;405:183-187.

34 Bolcskei K, Helyes Z, Szabo A, Sandor K, Elekes K, Nemeth J, Almasi R, Pinter E, Petho G, Szolcsanyi J: Investigation of the role of TRPV1 receptors in acute and chronic nociceptive processes using gene-deficient mice. Pain 2005;117:368-376.

35 Yaksh TL, Farb DH, Leeman SE, Jessell TM Intrathecal capsaicin depletes substance P in the rat spinal cord and produces prolonged thermal analgesia. Science 1979;206:481483.

36 Nagy JI, Emson PC, Iversen LL: A re-evaluation of the neurochemical and antinociceptive effects of intrathecal capsaicin in the rat Brain Res 1981;211:497-502.

37 Cavanaugh DJ, Lee H, Lo L, Shields SD, Zylka MJ, Basbaum AI, Anderson DJ: Distinct subsets of unmyelinated primary sensory fibers mediate behavioral responses to noxious thermal and mechanical stimuli. Proc Natl Acad Sci USA 2009;106:9075-9080.

38 Simone DA, Ochoa J: Early and late effects of prolonged topical capsaicin on cutaneous sensibility and neurogenic vasodilatation in humans. Pain 1991;47:285-294.

39 Beydoun A, Dyke DB, Morrow TJ, Casey KL: Topical capsaicin selectively attenuates heat pain and A delta fiber-mediated laser-evoked potentials. Pain 1996;65:189-196.
40 Khalili N, Wendelschafer-Crabb G, Kennedy WR, Simone DA: Influence of thermode size for detecting heat pain dysfunction in a capsaicin model of epidermal nerve fiber loss. Pain 2001;91:241-250.

-41 Ragé M, Van Acker N, Facer P, Shenoy R, Knaapen MW, Timmers M, Streffer J, Anand P, Meert T, Plaghki L: The time course of $\mathrm{CO}_{2}$ laser-evoked responses and of skin nerve fibre markers after topical capsaicin in human volunteers. Clin Neurophysiol 2010;121: 1256-1266.

42 Malmberg AB, Mizisin AP, Calcutt NA, von Stein T, Robbins WR, Bley KR: Reduced heat sensitivity and epidermal nerve fiber immunostaining following single applications of a high-concentration capsaicin patch. Pain 2004;111:360-367.

43 Kennedy WR, Vanhove GF, Lu SP, Tobias J, Bley KR, Walk D, Wendelschafer-Crabb G, Simone DA, Selim MM: A randomized, controlled, open-label study of the long-term effects of NGX-4010, a high-concentration capsaicin patch, on epidermal nerve fiber density and sensory function in healthy volunteers. J Pain 2010;11:579-587.

44 Bernstein JE, Korman NJ, Bickers DR, Dahl MV, Millikan LE: Topical capsaicin treatment of chronic postherpetic neuralgia. J Am Acad Dermatol 1989;21:265-270.

$\checkmark 4$ The Capsaicin Study Group: Treatment of painful diabetic neuropathy with topical capsaicin: a multicenter, double-blind, vehicle-controlled study. Arch Intern Med 1991; 151:2225-2229.

46 Watson CP, Tyler KL, Bickers DR, Millikan LE, Smith S, Coleman E: A randomized vehicle-controlled trial of topical capsaicin in the treatment of postherpetic neuralgia. Clin Ther 1993;15:510-526.

-47 Biesbroeck R, Bril V, Hollander P, Kabadi U, Schwartz S, Singh SP, Ward WK, Bernstein JE: A double-blind comparison of topical capsaicin and oral amitriptyline in painful diabetic neuropathy. Adv Ther 1995;12:111120 .

48 Ellison N, Loprinzi CL, Kugler J, Hatfield AK, Miser A, Sloan JA, Wender DB, Rowland KM, Molina R, Cascino TL, Vukov AM, Dhaliwal HS, Ghosh C: Phase III placebocontrolled trial of capsaicin cream in the management of surgical neuropathic pain in cancer patients. J Clin Oncol 1997;15:29742980

49 Paice JA, Ferrans CE, Lashley FR, Shott S, Vizgirda V, Pitrak D: Topical capsaicin in the management of HIV-associated peripheral neuropathy. J Pain Symptom Manage 2000; 19:45-52.

50 Webster LR, Malan TP, Tuchman MM, Mollen MD, Tobias JK, Vanhove GF: A multicenter, randomized, double-blind, controlled dose finding study of NGX-4010, a high-concentration capsaicin patch, for the treatment of postherpetic neuralgia. J Pain 2010;11:972-982. 
51 Backonja M, Wallace MS, Blonsky ER, Cutler BJ, Malan P Jr, Rauck R, Tobias J: NGX-4010, a high-concentration capsaicin patch, for the treatment of postherpetic neuralgia: a randomised, double-blind study. Lancet Neurol 2008;7:1106-1112.

52 Backonja MM, Malan TP, Vanhove GF, Tobias JK: NGX-4010, a high-concentration capsaicin patch, for the treatment of postherpetic neuralgia: a randomized, double-blind, controlled study with an open-label extension. Pain Med 2010;11:600-608.

53 Simpson DM, Brown S, Tobias J: Controlled trial of high-concentration capsaicin patch for treatment of painful HIV neuropathy. Neurology 2008;70:2305-2313.

54 Simpson DM, Gazda S, Brown S, Webster LR, Lu SP, Tobias JK, Vanhove GF: Longterm safety of NGX-4010, a high-concentration capsaicin patch, in patients with peripheral neuropathic pain. J Pain Symptom Man age 2010;39:1053-1064.

-55 Davies A, Hendrich J, Van Minh AT, Wratten J, Douglas L, Dolphin AC: Functional biology of the alpha(2)delta subunits of voltage-gated calcium channels. Trends Pharmacol Sci 2007;28:220-228.

56 Russell LC, Burchiel KJ: Neurophysiological effects of capsaicin. Brain Res 1984;320:165176.

57 Jancso G, Kiraly E, Jancso-Gabor A: Pharmacologically induced selective degeneration of chemosensitive primary sensory neurones. Nature 1977;270:741-743.

58 Maggi CA, Borsini F, Santicioli P, Geppetti P, Abelli L, Evangelista S, Manzini S, Theodorsson-Norheim E, Somma V, Amenta F: Cutaneous lesions in capsaicin-pretreated rats. A trophic role of capsaicin-sensitive afferents? Naunyn Schmiedebergs Arch Pharmacol 1987;336:538-545.

59 Jeffry JA, Yu SQ, Sikand P, Parihar A, Evans MS, Premkumar LS: Selective targeting of TRPV1 expressing sensory nerve terminals in the spinal cord for long lasting analgesia. PLoS One 2009; 4:e7021.

-60 Tender GC, Walbridge S, Olah Z, Karai L, Iadarola M, Oldfield EH, Lonser RR: Selective ablation of nociceptive neurons for elimination of hyperalgesia and neurogenic inflammation. J Neurosurg 2005;102:522-525.
61 Holzer P: The pharmacological challenge to tame the transient receptor potential vanilloid-1 (TRPV1) nocisensor. Br J Pharmacol 2008;155:1145-1162.

62 Carpenter SE, Lynn B: Vascular and sensory responses of human skin to mild injury after topical treatment with capsaicin. Br J Pharmacol 1981;73:755-758.

63 Culp WJ, Ochoa J, Cline M, Dotson R: Heat and mechanical hyperalgesia induced by capsaicin. Cross-modality threshold modulation in human C nociceptors. Brain 1989; 112:1317-1331.

64 Wood JN, Winter J, James IF, Rang HP, Yeats J, Bevan S: Capsaicin-induced ion fluxes in dorsal root ganglion cells in culture. J Neurosci 1988;8:3208-3220.

65 Fuchs PN, Campbell JN, Meyer RA: Secondary hyperalgesia persists in capsaicin desensitized skin. Pain 2000;84:141-149.

66 Chanda S, Sharper V, Hoberman A, Bley K: Developmental toxicity study of pure transcapsaicin in rats and rabbits. Int J Toxicol 2006;25:205-217.

67 Chanda S, Bashir M, Babbar S, Koganti A, Bley K: In vitro hepatic and skin metabolism of capsaicin. Drug Metab Dispos 2008;36: 670-675.

68 US Pharmacopeia: United States Pharmacopoeia, ed 28. National Formulary, 2005.

69 Attal N, Cruccu G, Baron R, Haanpaa M, Hansson P, Jensen TS, Nurmikko T: EFNS guidelines on the pharmacological treatment of neuropathic pain: 2010 revision. Eur J Neurol 2010;17:1113-1123, e67-e88.

70 Derry S, Lloyd R, Moore RA, McQuay HJ: Topical capsaicin for chronic neuropathic pain in adults. Cochrane Database Syst Rey 2009;CD007393.

71 Finnerup NB, Sindrup SH, Jensen TS: The evidence for pharmacological treatment of neuropathic pain. Pain 2010;150:573-581.

72 Maier C, Baron R, Tolle TR, Binder A, Birbaumer N, Birklein F, Gierthmuhlen J, Flor H, Geber C, Huge V, Krumova EK, Landwehrmeyer GB, Magerl W, Maihofner C, Richter H, Rolke R, Scherens A, Schwarz A, Sommer C, Tronnier V, Uceyler N, Valet M, Wasner G, Treede RD: Quantitative sensory testing in the German Research Network on Neuropathic Pain (DFNS): somatosensory abnormalities in 1,236 patients with different neuropathic pain syndromes. Pain 2010;150:439-450.
73 Jancso G, Kiraly E, Such G, Joo F, Nagy A: Neurotoxic effect of capsaicin in mammals. Acta Physiol Hung 1987;69:295-313.

74 Scadding JW: The permanent anatomical effects of neonatal capsaicin on somatosensory nerves. J Anat 1980;131:471-482.

75 Simone DA, Nolano M, Johnson T, Wendelschafer-Crabb G, Kennedy WR: Intradermal injection of capsaicin in humans produces degeneration and subsequent reinnervation of epidermal nerve fibers: correlation with sensory function. J Neurosci 1998; 18:89478959.

76 McMahon SB, Lewin G, Bloom SR: The consequences of long-term topical capsaicin application in the rat. Pain 1991;44:301-310.

77 European Commission: Scientific Committee on Food: Opinion of the Scientific Committee on Food on Capsaicin, 2002.

78 Babbar S, Marier JF, Mouksassi MS, Beliveau M, Vanhove GF, Chanda S, Bley K: Pharmacokinetic analysis of capsaicin after topical administration of a high-concentration capsaicin patch to patients with peripheral neuropathic pain. Ther Drug Monit 2009;31: 502-510.

79 Polydefkis M, Hauer P, Sheth S, Sirdofsky M, Griffin JW, McArthur JC: The time course of epidermal nerve fibre regeneration: studies in normal controls and in people with diabetes, with and without neuropathy. Brain 2004;127:1606-1615.

80 Gibbons CH, Wang N, Freeman R: Capsaicin induces degeneration of cutaneous autonomic nerve fibers. Ann Neurol 2010;68: 888-898.

81 Tandan R, Lewis GA, Badger GB, Fries TJ: Topical capsaicin in painful diabetic neuropathy. Effect on sensory function. Diabetes Care 1992;15:15-18.

82 Forst T, Pohlmann T, Kunt T, Goitom K, Schulz G, Lobig M, Engelbach M, Beyer J, Pfutzner A: The influence of local capsaicin treatment on small nerve fibre function and neurovascular control in symptomatic diabetic neuropathy. Acta Diabetol 2002;39: $1-6$. 